\title{
Block copolymers as dispersants and migration inhibitors: incorporation of fluorescent dyes in polyethylene
}

\author{
Kamal Hariri, ${ }^{1}$ Thomas Ruch, ${ }^{2}$ Gérard Riess ${ }^{1 *}$ \\ ${ }^{1}$ Laboratoire de Chimie Macromoléculaire (COBM), Ecole Nationale Supérieure de \\ Chimie de Mulhouse, 3 Rue Alfred Werner, 68200 Mulhouse, France; E-mail: \\ gerard.riess@uha.fr \\ ${ }^{2}$ Ciba Specialty Chemicals Inc., R-1059.3.05, P.O. Box, CH-4002 Basel, Switzerland
}

(Received: 06 July, 2008; published: 09 June, 2009)

\begin{abstract}
The problem of dye migration in PE which is of importance for coating and packaging applications was examined with fluorescent colorant C.I. Solvent Yellow 43 as a model of fluorescent dye poorly soluble in PE. These types of dyes are soluble in the PE melt, they show however a strong tendency to crystallize on cooling and to migrate on the surface giving rise to the typical blooming effect. It could be demonstrated by different migration tests that on addition of $P(E B)-b-P E O$ or SEBS block copolymers, having one sequence selectively miscible with PE, the other with the dye, prevent to a very large extent the dye migration and thus its surface crystallization (blooming). This improvement is attributed to the formation, in the PE amorphous phase, of PEO and PS microdomains respectively that are able to solubilize selectively the dye. By fluorescence spectroscopy it could be demonstrated that the dye is selectively solubilized in the PEO microdomains of the $\mathrm{P}(\mathrm{EB})$-b-PEO block copolymer, as well for micelles formed in heptane, as for the blends with PE.

Keywords: Fluorescent dyes, Block copolymers, Polyethylene, Crystallization, Migration, Packaging applications, Micelles, Fluorescence spectroscopy
\end{abstract}

\section{Introduction}

The increasing importance and interest in block copolymers arises from their unique properties in solution and in the solid state which are a consequence of their molecular structure. Due to their amphiphilic properties in solution and the formation of microdomains by phase separation in the solid state, they offer attractive application possibilities as emulsifiers, compatibilizers, dispersing agents, microreservoir systems, etc... [1-5]. This last aspect, essentially based on the solubilization capacity of block copolymer was extensively studied for the inclusion of hydrophobic compounds, such as drugs or dyes, in the micellar core of colloidal systems that have found strong interest in biomedical, as well as in optoelectronic applications [6, 7, 8, 9].

Similar to micelle formation of block copolymers in selective solvents, micellar type systems in the solid state can be formed by dispersion of a Poly A - Poly B diblock copolymer in a Poly B homopolymer matrix as demonstrated by Hashimoto et al. [10, 11] and later on by several other authors [12]. Within these microdomains, essentially formed by the phase-separated Poly A sequences of the block copolymer, it becomes possible to solubilize selectively low molecular weight compounds, such as solvents, plasticizers, etc $[13,14]$. Advantage can be taken of this concept in order to control, or even inhibit, the migration of other formulation additives, such as 
antioxidants, stabilizers or plasticizers [15]. To the best of our knowledge, the selective solubilization of dyes in block copolymer microdomains dispersed in a polymer matrix has not been described before in order to prevent dye migration from colored plastic articles. This problem of dye migration is in fact of practical importance as for instance in coating and packaging applications [16].

Our approach will be focused on the dye migration in polyethylene (PE) where it has been noticed that dyes solubilized in a polymer melt could have a tendency to phase separate and to crystallize on cooling if their solubility decreases [17]. This so-called blooming effect was also observed by Lazare and Billingham for poly(ester-blockether) copolymers additives such as UV-stabilizers [18]. For PE/dye blends the migration phenomena, leading to the formation of the dye crystals on the PE surface, is even enhanced due to the fact that on cooling a melt blend, the dye is rejected from the crystalline in the amorphous PE zones of low $T_{g}$, where its concentration could be largely over its solubility limit.

Different procedures have been reported to avoid dye migration in polyolefins. The one is that of covalently linked dyes in a polymer chain, obtained by copolymerization of a functionalized dye with given monomers, such as acrylic monomers [19, 20]. The other consists in the encapsulation of the dye in core-shell nano- or microparticles [21-23]. Even if a real progress could be achieved with these approaches, they involve additional production costs. Moreover their dispersibility in various polymeric matrices in not yet optimized.

The aim of this study is to illustrate that polyolefin based block copolymers promote the dispersion in PE of an insoluble dye and that they reduce to a large extent its migration. The concept consists in the incorporation of a fluorescent dye as a micellar dispersion of a block copolymer Poly A - Poly B, this copolymer has to be selected in such a way that Poly $A$ is a PE compatible segment and Poly $B$, the micellar core forming segment, has to be selectively compatible with the dye. This concept of dye solubilization in micellar cores of block copolymers is schematically illustrated in Figure 1.

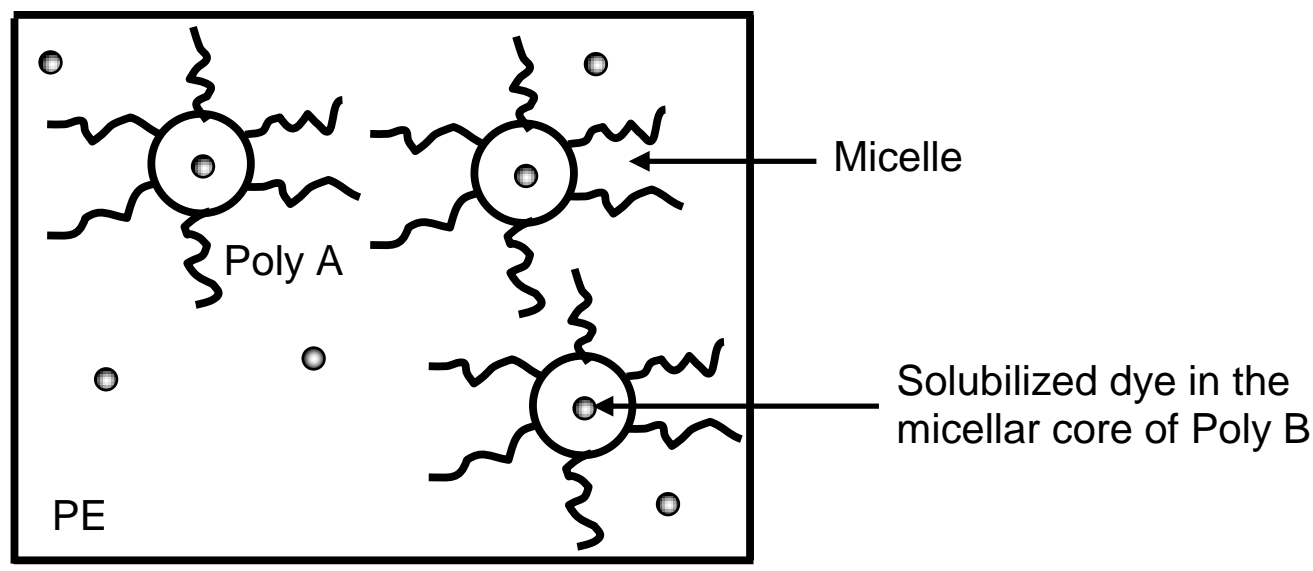

Fig. 1. Dye solubilization in the micellar core of a block copolymer PolyA - PolyB dispersed in a PE continuous phase - Schematic representation.

For analytical reasons a fluorescent dye such as C.I. Solvent Yellow 43, was selected. This dye, designated by Dye 1 in this study, is insoluble in aliphatic solvents 
and in PE at room temperature. Its melting point of $128{ }^{\circ} \mathrm{C}$ is in the same range as that of low density PE (LDPE), which facilitates its dispersion in the polymer melt.

The block copolymers meeting the above mentioned requirements were of two types: poly(ethylene-co-butylene)-block-poly(ethylene oxide), P(EB)-b-PEO and poly styrene-poly(ethylene-co-butylene)-polystyrene, SEBS.

\section{Results and discussion}

For a systematic approach of the ternary system block copolymer / dye / PE, the starting components as well as the corresponding binary systems were examined successively.

The $P(E B)-b-P E O$ block copolymer, with a $P E$ compatible $P(E B)$ sequence and a polar PEO block are very versatile amphiphilic components. They have been used to a large extent as emulsifiers and dispersants in aqueous and non-aqueous systems [24-27].

In its pure state, the PEO moiety has a tendency to partially crystallize with a melting point peak at $59{ }^{\circ} \mathrm{C}$ and a corresponding enthalpy of $83.3 \mathrm{~J} / \mathrm{g}$ as determined by DSC. By taking into account the copolymer composition of $57 \mathrm{wt} \% \mathrm{PEO}$ and the melting enthalpy of pure PEO of $188 \mathrm{~J} / \mathrm{g}$ [28], one can calculate that $78 \%$ of the PEO is in its crystalline form. The remaining amorphous PEO appears with a $\mathrm{T}_{\mathrm{g}}$ at around $-60{ }^{\circ} \mathrm{C}$. Depending on the cooling conditions the recrystallization occurs partially between 30 and $40^{\circ} \mathrm{C}$.

SEBS is typically an amorphous two-phase polymeric material, with PS microdomains having a $T_{g}$ of $82{ }^{\circ} \mathrm{C}$ and a continuous $P(E B)$ phase with a $T_{g}$ of -49 ${ }^{\circ} \mathrm{C}$.

As outlined in the experimental part, Dye 1 belongs to the class of naphthalimides series with $\mathrm{R} 1=\mathrm{R} 2=\left(\mathrm{CH}_{2}\right)_{3}-\mathrm{CH}_{3}$ substituents. The characteristics of these fluorescent dyes can be varied to a large extent as a function of the substituents as shown by Alexiou et al. [29]. Dye 1 has been selected as a "model" for this study for the following reasons. At first, its melting point peak of $128{ }^{\circ} \mathrm{C}$, is in the same range as that of $\mathrm{PE}$; this would facilitate its dispersion and solubilization in the polymer melt. At a cooling rate of $10{ }^{\circ} \mathrm{C} / \mathrm{min}$ no direct recrystallization can be observed, however the undercooled system crystallizes progressively on storage, a typical situation that contributes to the blooming effect of the dye.

Furthermore, the solubility parameter of Dye 1, calculated according to the theory of Hoftyzer and Van Krevelen [30], appears as shown in Table 1 to be close to that of PEO and PS, rather than to PE.

Tab. 1. Solubility parameters of the fluorescent dye, PEO, PS and PE.

\begin{tabular}{|c|c|c|c|c|c|}
\hline Component & $\begin{array}{c}\delta_{t} \\
\left(J^{1 / 2} / \mathrm{cm}^{3 / 2}\right)\end{array}$ & $\begin{array}{c}\delta_{d} \\
\left(J^{1 / 2} / \mathrm{cm}^{3 / 2}\right)\end{array}$ & $\begin{array}{c}\delta_{p} \\
\left(J^{1 / 2} / \mathrm{cm}^{3 / 2}\right)\end{array}$ & $\begin{array}{c}\delta_{h} \\
\left(J^{1 / 2} / \mathrm{cm}^{3 / 2}\right)\end{array}$ & $\left(\delta_{p}{ }^{2}+\delta_{h}{ }^{2}\right)^{1 / 2}$ \\
\hline Dye 1 & 22.8 & 20.7 & 6.2 & 7.4 & 9.6 \\
\hline PEO & 21.4 & 16.7 & 10.1 & 8.7 & 13.3 \\
\hline PS & 19.3 & 16.7 & 8.2 & 5.2 & 9.7 \\
\hline PE & 16.2 & 16.0 & 0.8 & 2.8 & 2.9 \\
\hline
\end{tabular}


By taking into account, according to Slark [31], as well $\delta_{t}$ as the mean values $\left(\delta_{p}{ }^{2}+\right.$ $\left.\delta_{h}^{2}\right)^{1 / 2}$ of the polar contributions, it appears in a first approach that at $25^{\circ} \mathrm{C}$ Dye 1 is preferably soluble in a PEO and PS rather than in the PE phase. A further evidence that the partition coefficient of the Dye 1 is in favor of the PEO phase could be given by checking its solubility in a liquid two-phase system, such as poly(ethylene glycol) (PEG 300) and heptane, having similar solubility parameters to those of PEO and $P(E B)$ respectively. From this simple test it appears that Dye 1 is selectively soluble in PEG 300.

The binary system PE + P(EB)-b-PEO block copolymer corresponds to a typical situation of a homopolymer / block copolymer blend, that have been examined in detail by Hashimoto et al. [10,11] and later on by Jeong [12] in the simpler cases of non-crystallizable components. Micro- and macrophase separation could be observed as a function of blend composition, molecular weight and interaction parameters of the components.

The situation is much more complex for a semi-crystalline polymer, such as $\mathrm{PE}$ as major component, blended with crystalline-amorphous a $P(E B)-b-P E O$ block copolymer. On cooling from the melt, PE starts to crystallize whereby the PEO block will be in a confined situation, which strongly influences the crystallization of the phase-separated PEO, as demonstrated by Huang et al. [32] for a PEO-b-PB diblock copolymer in a polybutadiene (PB) non-crystallizable matrix.

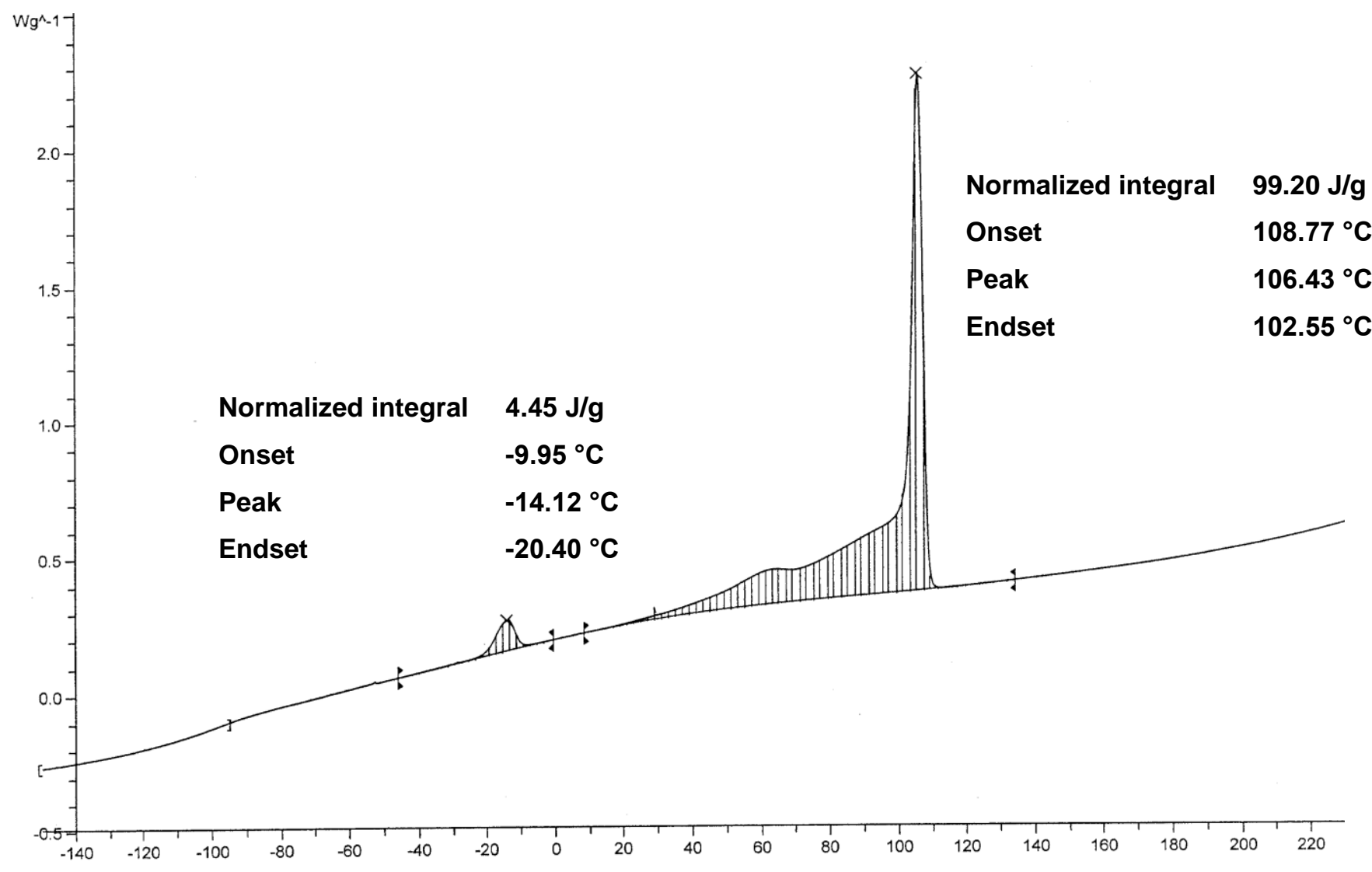

Fig. 2. DSC of a PE and $P(E B)-b-P E O$ blend with 10 wt\% block copolymer. 
In the present case, that of $\mathrm{PE}$ and $\mathrm{P}(\mathrm{EB})-\mathrm{b}-\mathrm{PEO}$ blends with $10 \mathrm{wt} \%$ block copolymer, DSC reveals that on cooling only a partial crystallization of PEO occurs at a relatively low temperature, around $-14^{\circ} \mathrm{C}$, as shown in Figure 2 .

The same situation was observed for the corresponding blend containing $1 \mathrm{wt} \%$ Dye 1 , added in form of dye / copolymer master-batch as indicated in the experimental part.

Taking into account the crystallization enthalpy of the PEO peak at $-14^{\circ} \mathrm{C}$, it can be concluded that around $40-50 \%$ of the PEO from the block copolymer is in phaseseparated amorphous state dispersed in the non-crystalline domains of PE. Dye 1, which is selectively soluble in PEO, can therefore be considered as to be solubilized in these PEO domains.

In order to demonstrate the blooming effect of Dye 1 in a PE matrix and the beneficial effect of $P(E B)-b-P E O$ block copolymers, the two following blends were compared at a same total concentration of $0.1 \mathrm{wt} \%$ dye with respect to PE. For the first sample, 0.1 wt\% of dye was added directly into the PE melt without copolymer. In the second case $10 \mathrm{wt} \%$ copolymer and $0.1 \mathrm{wt} \%$ of Dye 1 were added successively to the PE melt. Both film surfaces were examined by SEM (Scanning Electronic Microscopy), as shown in Figure 3.
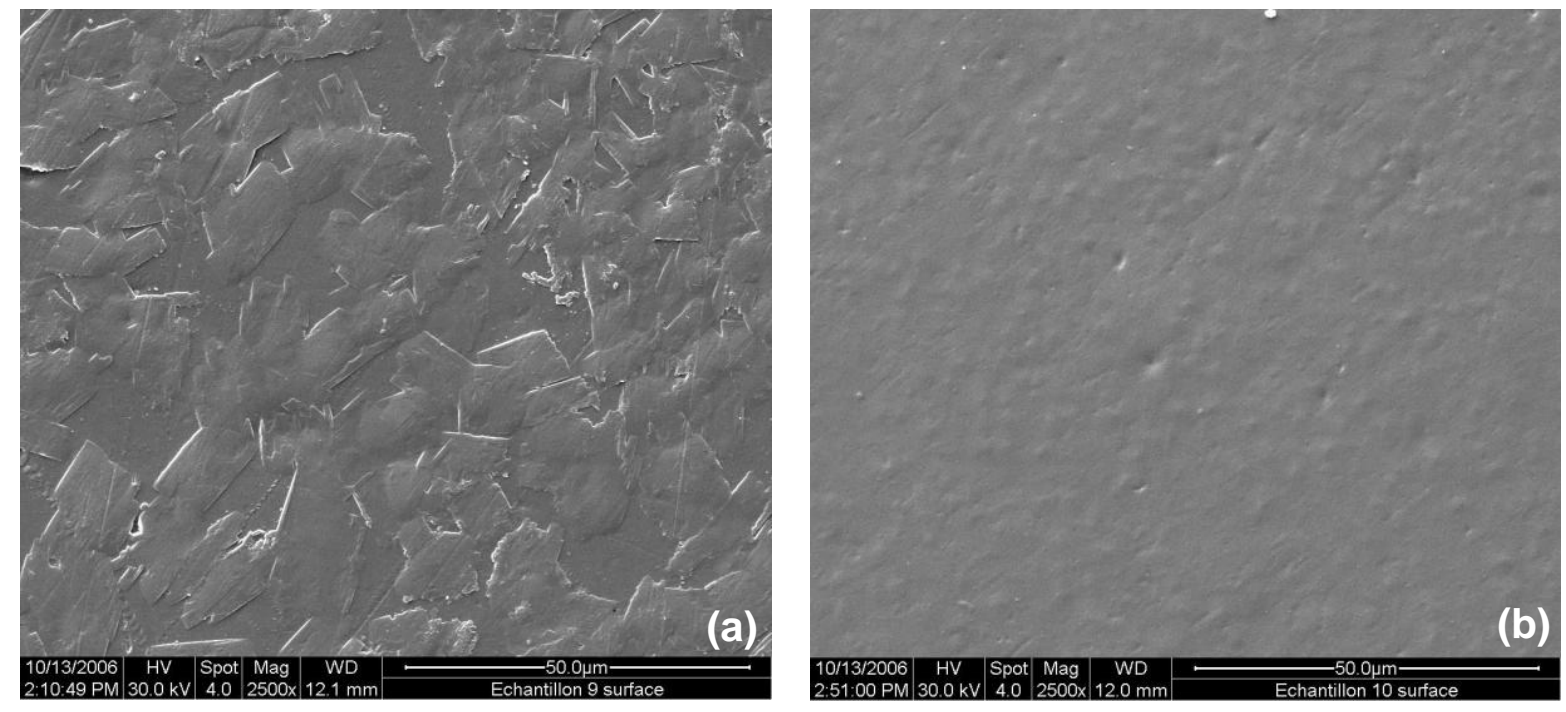

Fig. 3. SEM photographs - Surface analysis : (a) PE + Dye 1 (0.1\%) (without copolymer), (b) PE + Dye $1(0.1 \%)+P(E B)-b-P E O(10 \%)$.

It can clearly be observed that without added block copolymer, dye crystals have been formed on the film surface during the cooling stage and within a short period ( 1 day) of storage at room temperature. In contrast, no dye blooming effect could be noticed under the same conditions, and even after 1 year storage, for the film prepared in the presence of block copolymer. In addition, to its beneficial effect as dye migration inhibitor, the block copolymer acts as a dispersion agent for the dye. The dye was perfectly dispersed in the film in the presence of block copolymer, whereas dye agglomerates subsisted in its absence. 
In a systematic and a quantitative approach of the dye migration, the influence of the main formulation parameters was examined with the normalized extraction tests indicated in the experimental part.

The first parameters which is that of the block copolymer concentration, varied from 0 to $15 \mathrm{wt} \%$ with respect to PE, by keeping a constant level of $0.02 \mathrm{wt} \%$ Dye 1 in the films. With a master-batch (M-B) at a dye concentration of $1 \mathrm{wt} \%$ in the $\mathrm{P}(\mathrm{EB})$-bPEO block copolymer, it turns out that at the fixed level of 0.02 wt\% Dye 1 with respect to PE, the final formulation will contain $2 \mathrm{wt} \%$ of copolymer with respect to PE.

At higher concentration of copolymer and keeping this level of 0.02 wt\% Dye 1 versus PE, additional amounts of copolymer have to be added as such. Consequently, there are the two possible blending sequences: $(P E+C o p)+M-B_{(1 \%)}$ and $\left(\mathbf{P E}+\mathbf{M}-\mathbf{B}_{(1 \%)}\right)+\mathbf{C o p}$ as indicated in detail in the experimental part. The corresponding results are indicated in Table 2 and Table 3.

Tab. 2. Dye migration tests: Influence of the copolymer concentration for the blending sequence $(\mathbf{P E}+\mathbf{C o p})+\mathbf{M}-\mathbf{B}_{(1 \%)}-$ Dye concentration $0.02 \mathrm{wt} \% / \mathrm{PE}$.

\begin{tabular}{|c|c|c|c|c|}
\hline Process & $\begin{array}{c}\text { P(EB)-b-PEO } \\
\text { (wt\% / PE) }\end{array}$ & $\begin{array}{c}\text { Absorbance } \\
\text { (AU) } \\
\text { (extraction } \\
\text { acetone) }\end{array}$ & $\begin{array}{l}\text { ppb into food } \\
\text { (extraction } \\
\text { ethanol / water) }\end{array}$ & $\begin{array}{l}\text { Notation } \\
\text { PVC }\end{array}$ \\
\hline PE + Dye 1 & 0 & $0.045 \pm 0.002$ & 3369 & 1 \\
\hline$P E+M-B_{(1 \%)}$ & 2 & 0.025 & 1894 & 2 \\
\hline $\begin{array}{c}(P E+C o p)+ \\
M-B_{(1 \%)}\end{array}$ & 5 & $0.009 \pm 0.001$ & 865 & 4 \\
\hline $\begin{array}{c}(P E+C o p)+ \\
M-B_{(1 \%)}\end{array}$ & 15 & $0.010 \pm 0.001$ & 842 & 4 \\
\hline
\end{tabular}

Tab. 3. Dye migration tests: Influence of the blending sequence at constant copolymer concentration (5wt\% / PE) - Comparison of the blending sequence (PE + Cop) + $\mathbf{M}-\mathbf{B}_{(1 \%)}$ and $\left(\mathbf{P E}+\mathbf{M}-\mathbf{B}_{(1 \%)}\right)+$ Cop - Dye concentration $0.02 \mathrm{wt} \% / \mathrm{PE}$.

\begin{tabular}{|c|c|c|c|c|}
\hline Process & $\begin{array}{c}\text { P(EB)-b-PEO } \\
\text { (wt \% / PE) }\end{array}$ & $\begin{array}{c}\text { Absorbance } \\
\text { (AU) }\end{array}$ & $\begin{array}{l}\text { ppb into food } \\
\text { (extraction } \\
\text { ethanol / water) }\end{array}$ & $\begin{array}{l}\text { Notation } \\
\text { PVC }\end{array}$ \\
\hline $\begin{array}{c}\text { (PE + Cop) + } \\
M^{-B_{(1 \%)}}\end{array}$ & 5 & $0.009 \pm 0.001$ & 865 & 4 \\
\hline $\begin{array}{c}\left(P E+M-B_{(1 \%)}\right) \\
+ \text { Cop) }\end{array}$ & 5 & $0.021 \pm 0.001$ & 1784 & $2-3$ \\
\hline
\end{tabular}

From Table 2, the following conclusions can be drawn: 
- The dye migration definitely decreases with increasing concentrations of block copolymer,

- The notations of the PVC tests vary from 1 to 4 , which is indicative of the reduced dye migration, in accordance with the solvent extraction tests.

- There is an excellent agreement between the different migration tests performed by extraction with acetone and with ethanol / water respectively.

According to the results from Table 3 , it seems that the preferred blending sequence is that designated by $(\mathbf{P E}+\mathbf{C o p})+\mathbf{M}-\mathbf{B}_{(1 \%)}$, where the additional amount of block copolymer is first blended with $\mathrm{PE}$, before addition of the master-batch.

The concept of blending PE with a master-batch of block copolymers and fluorescent dyes was extended by replacing the $\mathrm{P}(\mathrm{EB})$-b-PEO block copolymer by a SEBS triblock copolymer of PS and $P(E B)$. The results of these tests are summarized in Table 4.

Tab. 4. Dye migration tests: Influence of the copolymer concentration for the blending sequence $(\mathbf{P E}+\mathbf{C o p})+\mathbf{M}-\mathbf{B}_{(1 \%)}$ - Dye concentration $0.02 \mathrm{wt} \% / \mathrm{PE}$.

\begin{tabular}{|c|c|c|c|c|}
\hline Process & $\begin{array}{c}\text { SEBS } \\
\text { (wt } \% \text { / PE) }\end{array}$ & $\begin{array}{c}\text { Absorbance } \\
\text { (AU) } \\
\text { (extraction } \\
\text { acetone) }\end{array}$ & $\begin{array}{l}\text { ppb into food } \\
\text { (extraction } \\
\text { ethanol / water) }\end{array}$ & $\begin{array}{c}\text { Notation } \\
\text { PVC }\end{array}$ \\
\hline \multirow{4}{*}{$\begin{array}{c}\mathrm{PE}+\text { Dye 1 } \\
\mathrm{PE}+\mathrm{M}-\mathrm{B}_{(1 \%)} \\
(\mathrm{PE}+\mathrm{Cop})+ \\
\mathrm{M}-\mathrm{B}_{(1 \%)} \\
(\mathrm{PE}+\mathrm{Cop})+ \\
{\mathrm{M}-\mathrm{B}_{(1 \%)}}\end{array}$} & 0 & $0.045 \pm 0.002$ & 3369 & 1 \\
\hline & 2 & $0.034 \pm 0.001$ & 3045 & 1 \\
\hline & 5 & 0.024 & 1773 & 2 \\
\hline & 10 & $0.024 \pm 0.002$ & 1673 & 2 \\
\hline
\end{tabular}

One can notice a decrease of extracted dye as well by acetone as by ethanol / water with increasing copolymer concentrations. At a given copolymer concentration, more dye is extracted for the blends with SEBS than those prepared with a P(EB)-b-PEO block copolymer. A difference in efficiency appears also by considering the notations of the PVC tests, which level off at a value of 2 for blends containing 5 and $10 \%$ SEBS respectively. It has to be kept in mind that this comparison is only of qualitative order, due to the fact that the SEBS copolymer contains only 29 wt\% PS as PE incompatible block, whereas the P(EB)-b-PEO has a PEO content of 57 wt\%. However, even by considering comparable amounts of PEO and PS contents, it appears that $\mathrm{P}(\mathrm{EB})$-b-PEO is still more efficient than SEBS to reduce the dye migration.

These different results are summarized in Figure 4, showing that the dye extraction with acetone decreases with increasing concentrations of block copolymer, as well for $\mathrm{P}(\mathrm{EB})-\mathrm{b}-\mathrm{PEO}$ as for SEBS.

A preliminary spectroscopic study was carried out in order to demonstrate that Dye 1 is selectively incorporated in the PEO microdomains of the $P(E B)-b-P E O$ block copolymers and thus in the PEO phase of its blends with PE. 


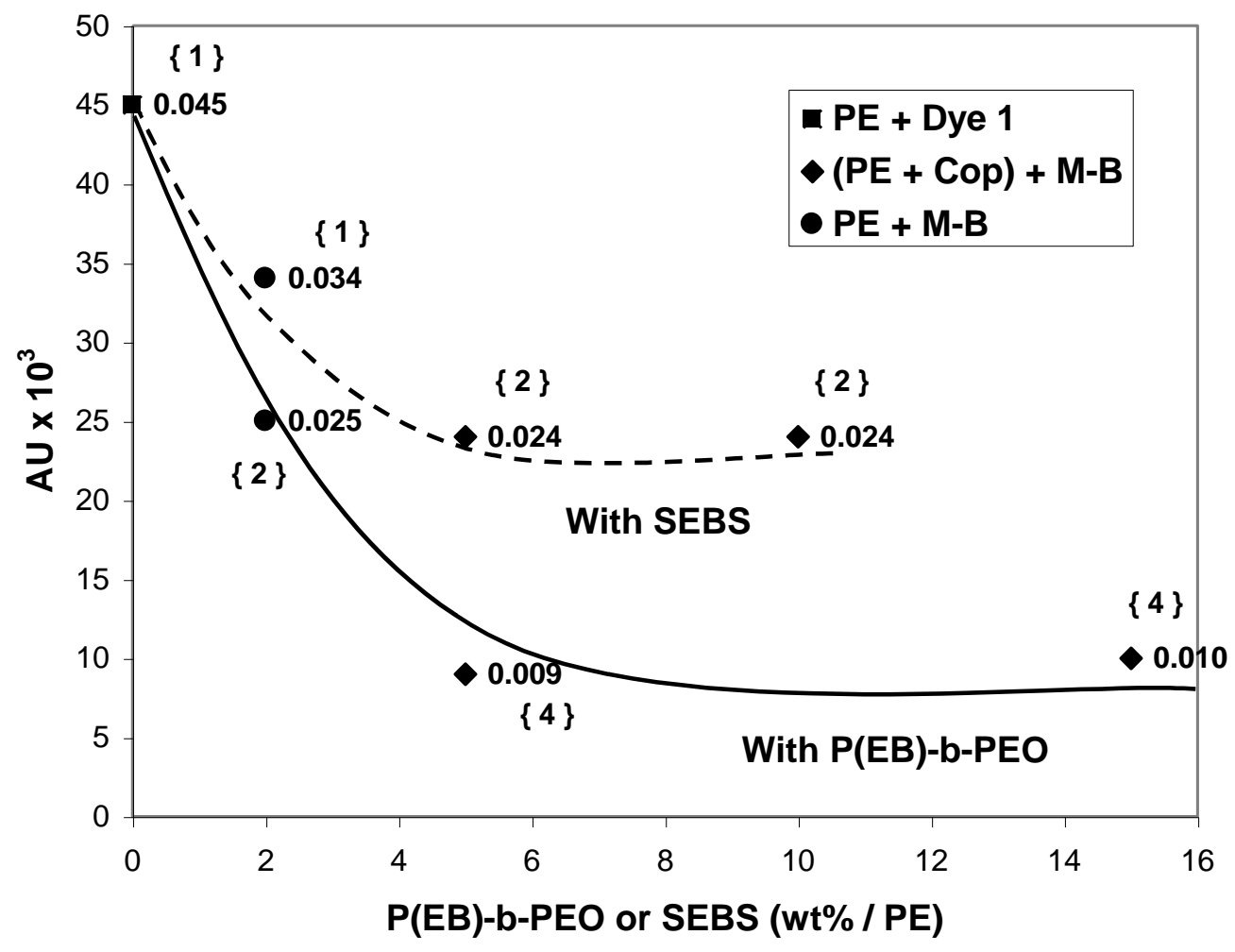

Fig. 4. Absorbance vs concentration of $P(E B)-b-P E O$ or SEBS - \{\} : value of the PVC migration tests.

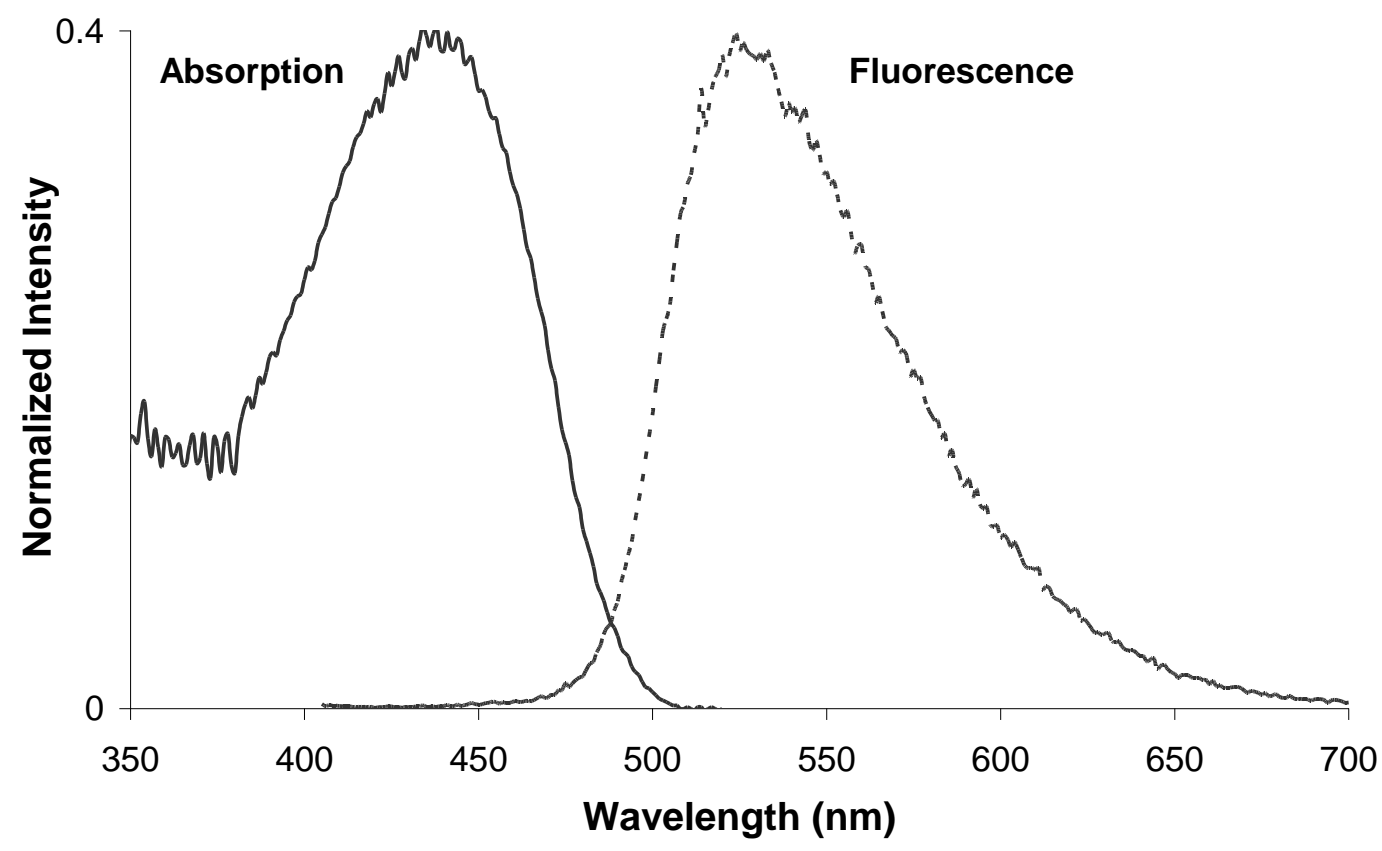

Fig. 5. Absorption and fluorescence spectra of a PE Film with $0.02 w t \%$ Dye 1 and $5 w+\%$ P(EB)-b-PEO block copolymer. 
Figure 5 shows the absorption and fluorescence spectra of a PE film containing 0.02 wt\% Dye 1 and 5 wt\% $\mathrm{P}(\mathrm{EB})$-b-PEO block copolymer. It is worth noting the absorption maximum at $440 \pm 3 \mathrm{~nm}$ which corresponds to that of Dye 1 in a polar solvent such as ethanol $\left(\lambda_{\max }=443.6 \mathrm{~nm}\right)$ or DMF $\left(\lambda_{\max }=439.5 \mathrm{~nm}\right)$. The maximum of the fluorescence spectra at $526 \pm 3 \mathrm{~nm}$ is that determined for Dye 1 in ethanol ( $\lambda_{\max }=526 \mathrm{~nm}$ or $525 \mathrm{~nm}$ according to reference [29]).

A further evidence that Dye 1 is essentially concentrated in the polar PEO phase can be obtained from the spectroscopic characteristics of this dye in a "model" system where the PE polymer phase is replaced by an hydrocarbon solvent, such as heptane. This model system has the advantage that the micellar size of the block copolymer becomes accessible and that the light scattering effects, arising from the PE crystals in the film, as observed for the absorption and fluorescence spectra in Figure 5, become almost negligeable.

By dynamic light scattering (DLS), it could be shown that the average micelle size of the $\mathrm{P}(\mathrm{EB})-\mathrm{b}-\mathrm{PEO}$ block copolymer, at a concentration of $2 \mathrm{wt} \%$ in heptane is $28 \mathrm{~nm}$, with no significant change of this volume average diameter by incorporation of $1 \mathrm{wt} \%$ Dye with respect to the block copolymer.

Such a micellar system with 2 wt\% block copolymer and $0.02 w t \%$ Dye 1 with respect to heptane, is typically in the concentration range of dye and copolymer in the PE film. Taking into account that the copolymer has a PEO content of $57 \mathrm{wt} \%$, a straightforward calculation shows that the molar dye concentration is very low, as it corresponds to 0.4 mole dye per $100 \mathrm{EO}$ monomer units. At this level, self-quenching of the dye in the PEO phase might most probably be very limited.

The fluorescence spectrum of the micellar system, formed by 2 wt\% P(EB)-b-PEO block copolymer and 0.02 wt\% Dye 1 in heptane, as well as the spectrum of the heptane soluble dye fraction are shown in Figure 6.

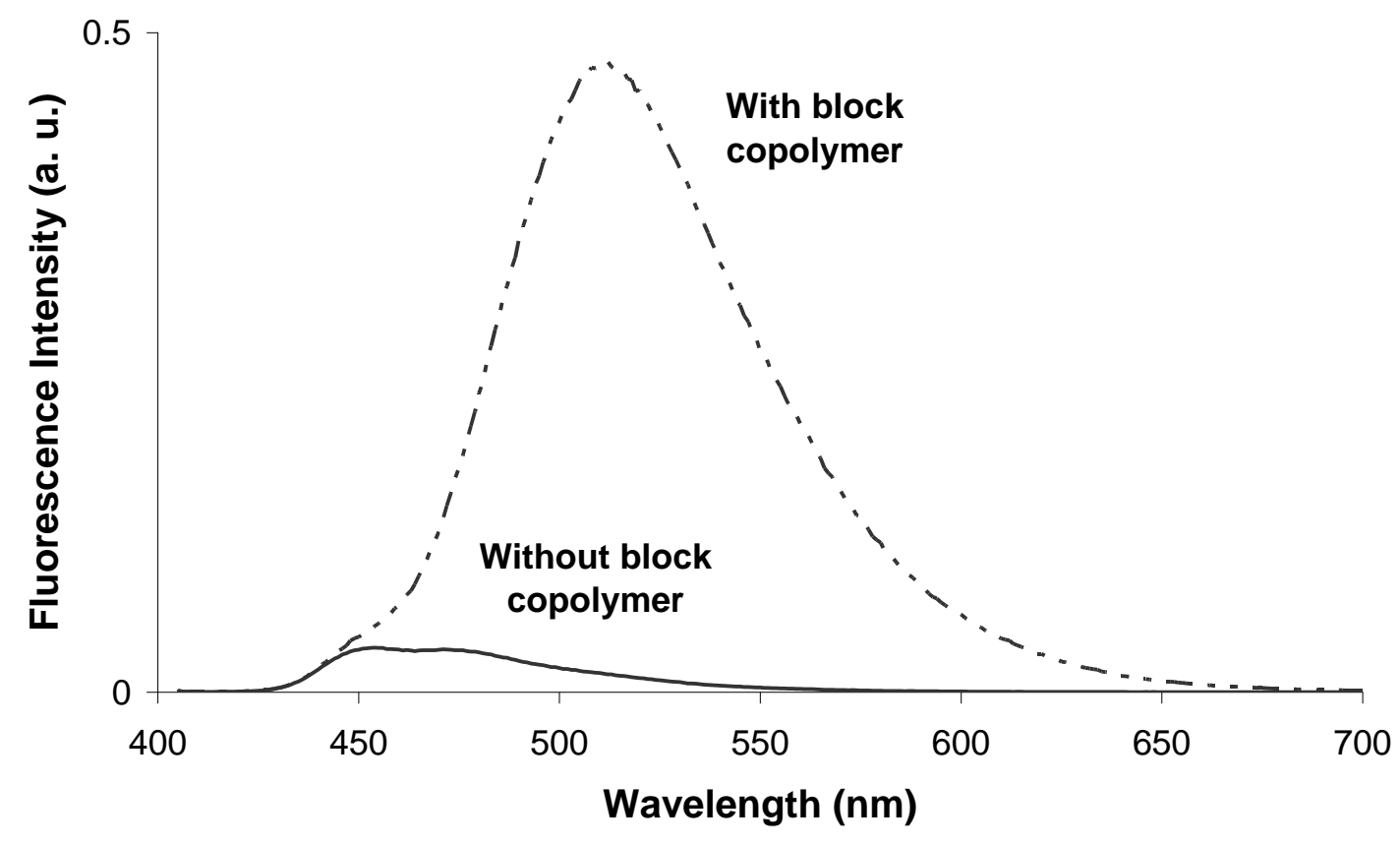

Fig. 6. Fluorescence spectra of the Dye 1 in heptane in presence of and without block copolymer (see text). 
In the presence of block copolymer, the maximum of the fluorescence spectrum appears at around $512-515 \mathrm{~nm}$, which is typical for the dye in a polar environment such as PEO.

The weak shoulder of the spectrum that can be noticed at around $450 \mathrm{~nm}$ arises from a slight solubility of the dye in heptane, at an estimated concentration of $1 \mathrm{wt} \%$ in heptane as determined by gravimetry. The maximum of this shoulder corresponds in fact to the fluorescence maximum of $453 \mathrm{~nm}$ as determined for the dye soluble fraction in heptane in the absence of block copolymer.

Further studies are in progress on the encapsulation of fluorescent dyes in block copolymer micellar systems.

\section{Conclusions}

With this contribution to the problem of dye migration in PE, it could be shown from a practical point of view that the surface migration and crystallization of the dye, the socalled blooming effect, could be suppressed with P(EB)-b-PEO or SEBS block copolymers. These types of block copolymers, with a PE incompatible PEO or PS sequence, by forming phase-separated PEO or PS microdomains, are able to solubilize selectively the dye. The dye concentration in the amorphous PE domains is thus reduced to a large extent. The more severe solvent extraction tests confirmed that these block copolymers are efficient additives to reduce significantly the dye migration. Even if the goal reached up to now might not be sufficient for food packaging applications, the concept of block copolymers as dispersing and solubilization agent of formulation additives, such as dyes, could nevertheless be of interest for coating and printing ink applications.

\section{Experimental part}

\section{Materials}

The fluorescent dye C.I. Solvent Yellow 43 of the naphtalimides series, also designated by Dye 1 in this study, was supplied by James Robinson Ltd., UK and has following structure:

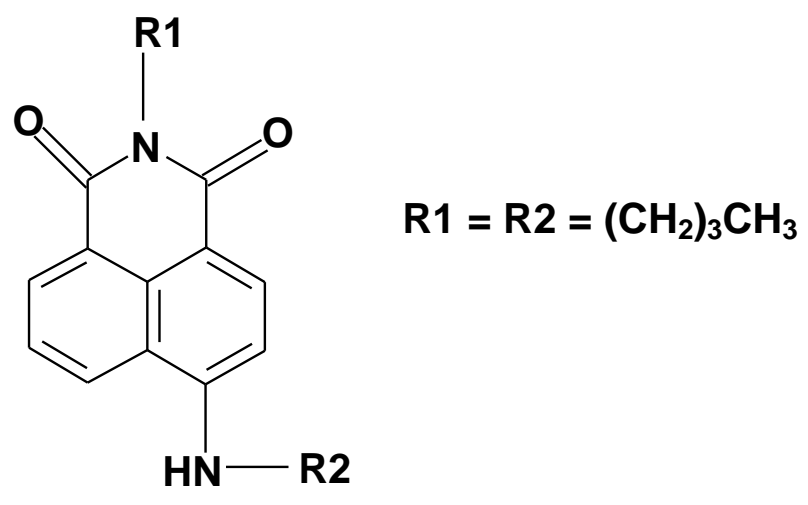

This dye has a melting point peak of $128{ }^{\circ} \mathrm{C}$. Its purity of at least $99 \%$ was checked by ${ }^{1} \mathrm{H}$ NMR in DMSO and by mass spectroscopy (HPLC-MS). Its molar extinction coefficients are the following: in ethanol $\varepsilon=16570\left(\lambda_{\max }=443.6 \mathrm{~nm}\right)$; in DMF $\varepsilon=$ $15407\left(\lambda_{\max }=439.5 \mathrm{~nm}\right)$. These values are in agreement with those indicated by 
Alexiou et al. [29]. The fluorescence properties of Dye 1 in ethanol given by these authors are the following: quantum yield $\varphi_{f}=0.810$; lifetime $\tau_{f}=10.5 \mathrm{~ns} ; \lambda_{\max }=525$ $\mathrm{nm}$.

The absorption and the fluorescence spectra, in heptane and in ethanol are shown in Figure 7.
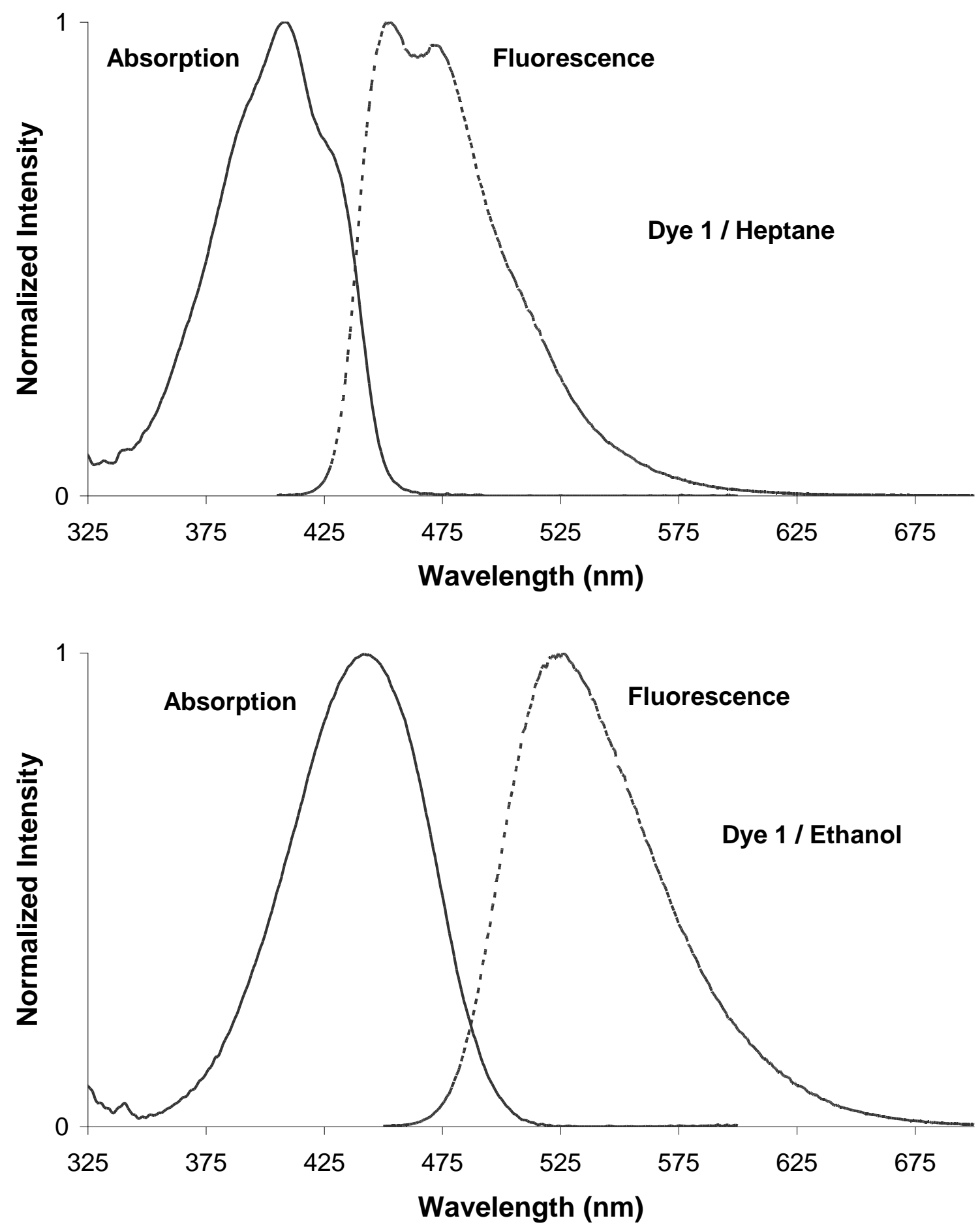

Fig. 7. Absorption and fluorescence spectra of the Dye 1 in heptane and in ethanol. 
It should be noticed that Dye 1 is completely soluble in polar solvents, such as ethanol, whereas the spectra in heptane corresponds to the slightly soluble fraction of that dye in hydrocarbon solvents.

The block copolymer poly(ethylene-co-butylene)-block-poly(ethylene oxide) poly(EB)b-PEO (molecular weight of $P(E B)=3700 \mathrm{~g} / \mathrm{mol}$, molecular weight of $\mathrm{PEO}=4900$ $\mathrm{g} / \mathrm{mol}$ ) having a weight content of $57 \%$ of PEO, was provided by Dr. P. Hoerner. The structure of this copolymer is the following:

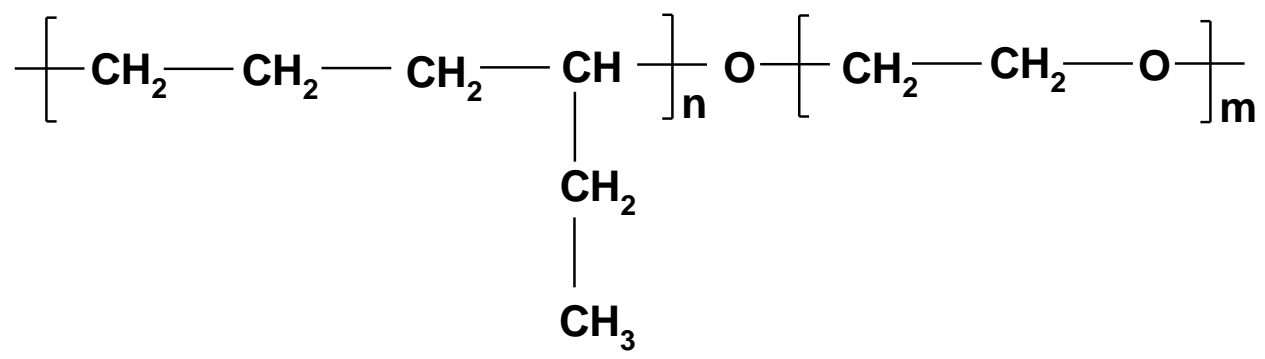

According to Schulz et al. [33] the polyolefinic sequence corresponds on the average to $67 \mathrm{~mol} \%$ ethylene units and $33 \mathrm{~mol} \%$ butylene units. This copolymer, available as a $50 \mathrm{wt} \%$ solution in xylene, was vacuum dried to constant weight at $60^{\circ} \mathrm{C}$ before use.

The copolymer SEBS Polystyrene-Poly(ethylene-co-butylene)-Polystyrene (molecular weight of $P(E B)=37600 \mathrm{~g} / \mathrm{mol}$, total molecular weight of $P S=15400$ $\mathrm{g} / \mathrm{mol}$ ) with $29 \mathrm{wt} \%$ of PS was provided by SHELL. The structure of this copolymer is the following:<smiles>CCC(CCCCCC(CC)c1ccccc1)CCC(C)C(CC)c1ccccc1</smiles>

For all the tests a LDPE (low density polyethylene) supplied by Exxon Chemical was used. Its melting and crystallization peaks were at 127 and $104{ }^{\circ} \mathrm{C}$ respectively. The crystallinity corresponded to $42 \%$.

\section{Preparation of samples}

\section{-Preparation of master-batch}

The master-batch (dye / block copolymer) was prepared, if not specified otherwise, by incorporating $1 \mathrm{wt} \%$ of fluorescent dye (Dye 1) in block copolymer P(EB)-b-PEO. This operation was carried out in a BRABENDER mixer at $150{ }^{\circ} \mathrm{C}$ (rotation speed $=$ 40 rpm during 30 minutes).

\section{-Incorporation of master-batch in PE}

This operation was carried out in BRABENDER mixer at $150{ }^{\circ} \mathrm{C}$ (rotation speed $=40$ rpm during 30 minutes). The blends were prepared at constant concentration of 0.02 
wt\% dye with respect to $\mathrm{PE}$, but with variable concentrations of copolymer, from 0 to 15 wt\% with respect to PE. Two possibilities concerning the mixing sequence of the components were tested:

- mixing at first at $150{ }^{\circ} \mathrm{C}$ the $\mathrm{PE}$ with the required amount of additional $\mathrm{P}(\mathrm{EB})-\mathrm{b}-$ PEO block copolymer during 30 minutes, and then introducing the given amount of dye master-batch and then mixing during 30 minutes. This procedure is indicated as: $(\mathbf{P E}+\mathbf{C o p})+\mathbf{M}-\mathbf{B}_{(1 \%)}$,

- mixing at first at $150{ }^{\circ} \mathrm{C}$ the PE with $2 \mathrm{wt} \%$ of dye master-batch (in order to have the constant concentration of 0.02 wt\% dye in PE) during 30 minutes, then introducing the given amount of block copolymer and then mixing during 30 minutes. This procedure is indicated as: $\left(\mathbf{P E}+\mathbf{M}-\mathbf{B}_{(1 \%)}\right)+\mathbf{C o p}$.

-Formation of films

The films were formed by compression moulding on a hotplate press at $150{ }^{\circ} \mathrm{C}$ between 2 Mylar sheets (polyester terephthalate). They were then cooled from 150 ${ }^{\circ} \mathrm{C}$ to room temperature within 10 to 15 minutes. Their thickness is in the range of 0.4 to $1 \mathrm{~mm}$.

\section{Characterization of samples}

\section{-SEM (Scanning Electronic Microscopy)}

SEM (Philips 525M) at an excitation energy of $30 \mathrm{kV}$ was used to study the morphology of the PE blends.

-Dye extraction tests

The extraction tests were performed with acetone and with a mixture ethanol / water (95 / 5):

- Extraction by acetone: In films thus formed were cut in pieces of $1 \mathrm{~cm} \times 2 \mathrm{~cm}$, which corresponds to weight generally ranging between 80 and $120 \mathrm{mg}$. They were then immersed in $10 \mathrm{ml}$ of acetone at room temperature during 5 days. No significant increase in dye desorption could be observed for longer extraction periods, such as 13 days. Acetone was selected as extraction solvent because it is a selective solvent of Dye 1 at room temperature. The acetone solutions were analyzed by UV-visible spectroscopy (Shimadzu UV$160 \mathrm{~A}$ ). The absorbance, determined at $437 \pm 5 \mathrm{~nm}$ with a $1 \mathrm{~cm}$ optical path, is given with respect to pure acetone.

- Extraction by mixture ethanol / water: 95 / 5: this type of solvent extraction was carried out under reflux during 2 hours on samples with a surface of $9 \mathrm{~cm} \times 7$ $\mathrm{cm}$ according to FDA specifications [34]. The amount of extracted dye, determined by UV-visible spectroscopy at $442 \mathrm{~nm}$ is given in ppb. This value is indicative of the dye amount that could migrate from the packaging into the food (preliminary fatty food simulation).

\section{-Dye migration tests}

These tests, performed under standard conditions, according to Norm DIN 53775 Part 3 (June 1984), are indicative of the dye migration from the colored PE film, into a plasticized PVC film. The notation from 1 to 5 is given by visual observation. A 
notation of 1 reveals important dye migration, whereas a notation of 5 indicates the absence of migration.

\section{-Absorption and Fluorescence spectroscopy}

The absorption and fluorescence spectra were obtained by using a Perkin-Elmer lambda 2 UV-Vis spectrophotometer and a Fluoromox-4 - Horiba Jobin Yvon spectrofluorometer respectively.

\section{-Dynamic Light Scattering (DLS)}

Dynamic light scattering measurements (DLS) of the micellar systems were performed with a Malvern Zetasizer Nano-ZS, light scattering spectrophotometer equipped with a red laser operating at $\lambda=633 \mathrm{~nm}$.

\section{Acknowledgements}

K. Hariri and G. Riess would like to thank CIBA Specialty Chemicals - Basel Switzerland, for the financial support of this study. The authors gratefully acknowledge Dr. P. Hoerner for providing P(EB)-b-PEO and Dr. J.-P. Malval for his kind assistance in the spectroscopy measurements.

\section{References}

[1] Lazzari, M.; Liu G.; Lecommandoux S. Block copolymers in nanoscience, WileyVCH, Weinheim 2006.

[2] Hamley, I.W. Developments in block copolymers, J. Wiley \& Sons, Chichester UK 2004.

[3] Riess, G. Prog. Polym. Sci. 2003, 28, 1107.

[4] Alexandridis, P. and Lindman, B. Amphiphilic block copolymers self assembly and applications, Elsevier, Amsterdam 2000.

[5] Hamley, I.W. The physics of block copolymers, Oxford Science Publ. 1998.

[6] Kataoka, K.; Harada, A.; Nagasaki, Y. Adv. Drug. Deliv. Rev. 2001, 47, 113.

[7] Kabanov, A.V.; Batrakova, E.V.; Alakhov, V.Y. J. Controlled Release 2002, 82, 189.

[8] Yoo, S.I.; Zin, W.C.; Kim, K.S.; Bae, S.H.; Sohn, B.H. ACS Polymer Preprints 2007, 48, 804.

[9] Yoshida, E.; Naito, T. Colloid Polym. Sci. 2008, 286, 1203.

[10] Hashimoto, T.; Tanaka, H.; Hasegawa, H. Macromolecules 1990, 23, 4378.

[11] Tanaka, H.; Hasegawa, H.; Hashimoto, T. Macromolecules 1991, 24, 240.

[12] Jeong, U.; Ryu, D.Y.; Kho, D.H.; Lee, D.H.; Kim, J.K.; Russell, T.P. Macromolecules 2003, 36, 3626.

[13] Gervais, M. and Gallot, B. Makromol. Chem. 1977, 178, 2071.

[14] Periard, J.; Banderet, A.; Riess, G. Angew. Makromol. Chem. 1971, $15,37$.

[15] Rixens, B.; Severac, R.; Boutevin, B.; Lacroix-Desmazes, P. Polymer 2005, 46, 3579.

[16] van den Oever, M.J.A.; Boeriu, C.G.; Blaauw, R.; van Haveren, J. J. Appl. Polym. Sci. 2004, 92, 2961.

[17] Herbst, W. and Hunger, K. Industrial organic pigments : production, properties, applications, VCH New York 1993, 63-119.

[18] Lazare, L. and Billingham, N.C. Polymer 2001, 42, 1001. 
[19] Kaul, B.L.; Graciet, J.-C.; Winnik, M. A.; Tronc, F.; Li, M.; Lu, J. Copolymer composition having pigment like properties, PCT : WO 02/066483 A1, 2002, US Patent : 7087677, 2006.

[20] Song, J.-S.; Tronc, F.; Winnik, M. A. Polymer 2006, 47, 817.

[21] Grabchev, I. and Guittonneau, S. Journal of Photochemistry and Photobiology A: Chemistry 2006, 179, 28.

[22] Bosma, G.; Pathmamanoharan, C.; de Hoog, E.H.A.; Kegel, W.K.; van Blaaderen, A.; Lekkerkerker, H.N.W. J. Colloid Interface Sci. 2002, 245, 292.

[23] $\mathrm{Hu}, \mathrm{H}$. and Larson, R.G. Langmuir 2004, 20, 7436.

[24] Landfester, K.; Willert, M.; Antonietti, M. Macromolecules 2000, 33, 2370.

[25] Lambreva, D.M.; Opitz, R.; Reiter, G.; Frederik, P.M.; de Jeu, W.H. Polymer 2005, 46, 4868.

[26] Hoerner, P. Synthesis and characterization of amphiphilic block copolymers : applications as emulsifier, PhD Thesis, University of Haute-Alsace, France, 1998.

[27] Krikorian, R. Crystallization in solution of block copolymer. Application to emulsion stabilization, PhD Thesis, University of Haute-Alsace, France, 2001.

[28] Mandelkern, L. J. Appl. Phys. 1955, 26, 443.

[29] Alexiou, M.S.; Tychopoulos, V.; Ghorbanian, S.; Tyman, J.H.P.; Brown, R.G.; Brittain, P.I. J. Chem. Soc. Perkin Trans. 2 1990, 5, 837.

[30] Hoftyzer, P.J. and Van Krevelen, D.W. Properties of polymers, Elsevier Science Publishers, $2^{\text {nd }}$ Edition 1976, Chapter 7, 152-155.

[31] Slark, A.T. Polymer 1997, 38, 2407.

[32] Huang, Y.-Y.; Yang, C.H. Chen, H.-L.; Chiu, F.-C.; Lin, T.-L.; Liou, W. Macromolecules 2004, 37, 486.

[33] Schulz, S.G.; Kuhn, H.; Schmid, G.; Mund, C.; Venzmer, J. Colloid Polym. Sci. 2004, 283, 284.

[34] U.S. Food and Drug Administration, Guidance for industry, Preparation of food contact notifications and food additive petitions for food contact substances: chemistry recommendations, CFSAN / Office of Food Additive Safety, April 2002, http://www.cfsan.fda.gov/ dms/opa2pmnc.html. 